\title{
Phylogenetic Evidence for the Transfer of Pseudomonas cocovenenans (van Damme et al. 1960) to the Genus Burkholderia as Burkholderia cocovenenans (van Damme et al. 1960) comb. nov.
}

\author{
NAIXIN ZHAO, ${ }^{1 *}$ CHUNFENG QU, ${ }^{1}$ ENTAO WANG, ${ }^{2}$ AND WENXIN CHEN ${ }^{2}$ \\ Weifang Medical College, Weifang, Shandong Province 261042, ${ }^{1}$ and Beijing Agricultural University, \\ Beijing 100094, ${ }^{2}$ People's Republic of China
}

\begin{abstract}
Pseudomonas cocovenenans, the producer of bongkrekic acid and toxoflavin, has been described previously by us (N.-X. Zhao, M.-S. Ma, Y.-P. Zhang, and D.-C. Xu, Int. J. Syst. Bacteriol. 40:452-455, 1990) in terms of more than 180 phenotypic traits, $G+C$ content, and DNA relatedness. The bacterium conformed to section II of the genus Pseudomonas. Here, its partial 16S rRNA gene sequence was compared with those of Burkholderia spp., and the results verified that $P$. cocovenenans is a Burkholderia species. On the basis of the phenotypic and genetic characteristics, $P$. cocovenenans is transferred to the genus Burkholderia as Burkholderia cocovenenans comb. nov.
\end{abstract}

The name Pseudomonas cocovenenans was first proposed for a food-poisoning bacterium in 1960 by van Damme et al. (12). The 1980 Approved Lists of Bacterial Names (8) included $P$. cocovenenans, and the article cited for a description of this organism was the article in which the name was proposed. However, in Bergey's Manual of Systematic Bacteriology (4) the following was said concerning this organism: "to our knowledge, no description of this species is available..."

In 1982 and 1988 (17) we described 17 strains of foodpoisoning bacteria isolated from sour fermented corn flour, a homemade product in the countryside of northeastern China, and showed that these conformed to Pseudomonas characteristics. The bacteria were also the cause of food poisoning caused by eating deteriorated (mildewed) Tremella fuciformis (white fungus). In cultivated T. fuciformis the contamination rate of the organism was ca. $50 \%$. The bacterium was not infectious to man and animals but its toxic metabolites induced the poisoning.

In 1990 we comparatively described $P$. cocovenenans NCIB $9450^{\mathrm{T}}$ and our 17 strains of the poisoning bacteria (16). Morphological, physiological, and biochemical reactions, the substrate utilization pattern, patterns of resistance and sensitivity to antibiotics, G+C content of DNA, and ca. 200 traits showed that the strains were similar. Furthermore, the antigenic relatedness and DNA relatedness showed the strains were closely homologous. From these findings, we concluded that (i) these strains are members of the same species, (ii) they conform to the definition of Pseudomonas spp., and (iii) they belong to Palleroni's section II of the genus. These strains were very similar to $P$. cepacia except for a few biochemical reactions and the outstanding property of producing bongkrekic acid and toxoflavin.

In 1988 Gwynn et al. (3) also identified and described $P$. cocovenenans, as a producer of a new member of the monobactam family of antibiotics, and their experimental results were very similar to ours $(16,17)$.

In 1992 Yabuuchi et al. (13) proposed a new genus Burkholderia for the RNA homology group II of the genus Pseudomonas on the basis of the 16S rRNA sequences, DNA-DNA homology values, cellular lipids, fatty acid composition, and phenotypic characteristics. Seven species in the group were

\footnotetext{
${ }^{*}$ Corresponding author.
}

transferred to the new genus with Burkholderia cepacia as the type species. In 1994 Urakami et al. transferred $P$. plantarii and $P$. glumae to the genus Burkholderia and described $B$. vandii as a new species (11).

We have reexamined the phenotypic characteristics and examined the main respiratory quinone of $P$. cocovenenans, determined partial sequences of its 16S rRNA gene, and propose that $P$. cocovenenans be transferred to the genus Burkholderia as Burkholderia cocovenenans (van Damme et al. 1960) comb. nov.

The strains used for phenotypic reexamination were NCIB $9450^{\mathrm{T}}$, NCIMB 12451 , and 16 other strains of $P$. cocovenenans $(16,17)$. The phenotypic characteristics were determined by methods described in the Manual of Methods for General Bacteriology (2) and the methods of Stanier et al. (9). The phenotypic characteristics were the same as those described previously by us (16) and others (3) except for some additional ones and revised ones as follows. Oxidase reaction was weakly positive as described in our previous article, but it was scored as negative, although it was different from the true negative reaction as in Enterobacter spp. Esculin was hydrolyzed. The strains did not utilize 2,3-butylene glycol as a sole carbon source. Growth was positive at $\mathrm{pH} 4.0$.

Respiratory quinone was assayed by the method of Collins (1a), and it was shown that the main quinone was ubiquinone Q-8.

The strain used for partial 16S rRNA gene nucleotide sequencing was $P$. cocovenenans NCIMB 12451 (T7707-a). This strain showed $95 \%$ DNA complementarity with the type strain of $P$. cocovenenans (NCIB 9450). The 16S rRNA gene of $P$. cocovenenans NCIMB 12451 was partially sequenced by the procedure of Young et al. (15). The primer Y1 (5'-TGGCT CAGAACGAACGCTGGCGGC-3') corresponds to positions 20 to 43 in the Escherichia coli 16S rRNA sequence, and the reverse primer, Y2 (5'-CCCACTGCTGCCTCCCGTAGGA GT-3'), corresponds to E. coli positions 361 to 338 . Genomic DNA from NCIMB 12451 provided the template from which a 291-bp segment of the 16S rRNA gene was amplified by PCR. This segment was then cloned in phage M13, and singlestranded DNA was extracted as described by Sambrook et al. (7). This fragment was sequenced by a model ABI-370A DNA sequencer.

The sequence (corresponding to positions 44 to 337 in the $E$. 


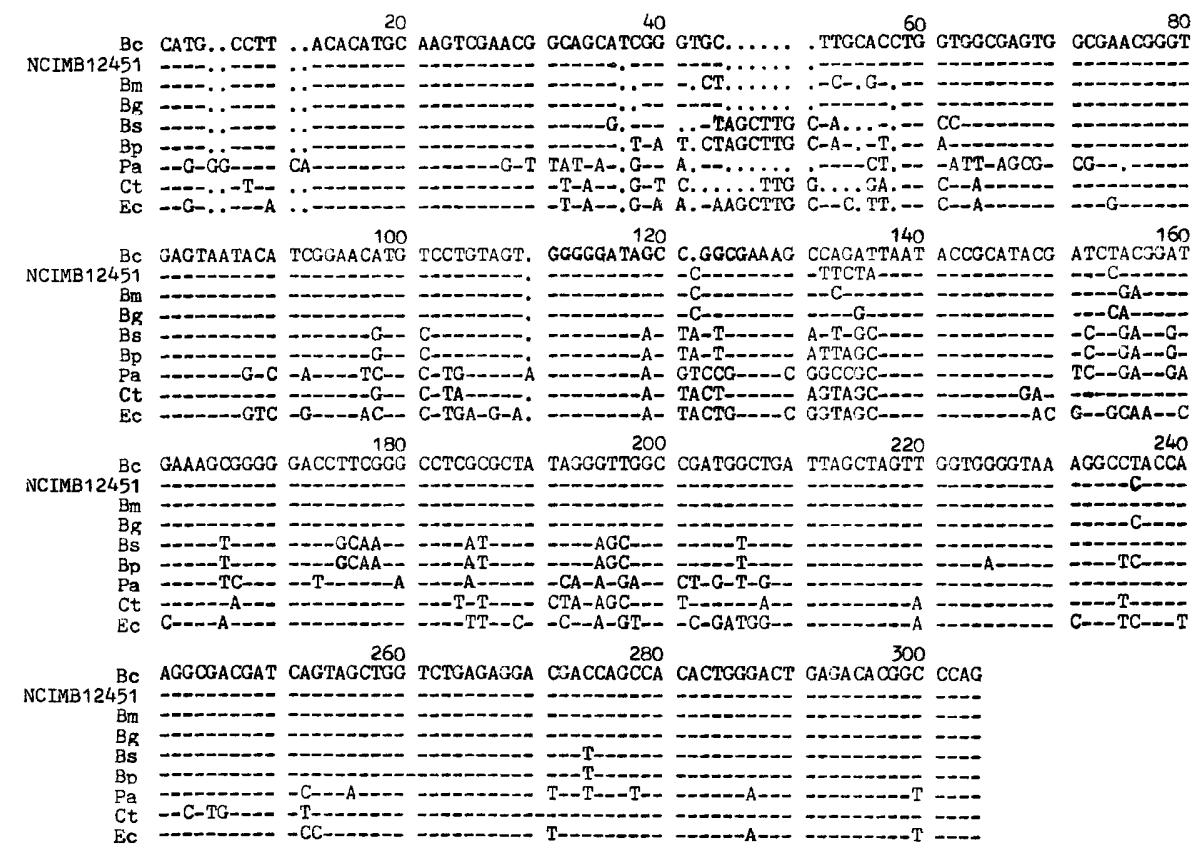

FIG. 1. Sequence alignment for $16 \mathrm{~S}$ rRNA gene fragments from B. cocovenenans NCIMB 12451, B. cepacia (Bc), B. mallei (Bm), B. gladioli (Bg), B. solanacerarum $(\mathrm{Bs}), B$. pickettii $(\mathrm{Bp}), P$. aeruginosa $(\mathrm{Pa}), C$. testosteroni $(\mathrm{Ct})$, and $E$. coli $(\mathrm{Ec})$. Dashes, identity with the $B$. cepacia sequence; dots, alignment gaps.

coli 16S rRNA sequence) of $P$. cocovenenans NCIMB 12451 was compared with published data on Burkholderia species (13), E. coli, P. aeruginosa (10), and Comamonas testosteroni (14). The partial 16S rRNA gene sequence and the alignment with sequences of other related bacteria are shown in Fig. 1. Positions 5, 6, 11, 12, and 37 to 58 were omitted because this loop varied in length among the sequences that were compared and could not be aligned unambiguously. Table 1 shows the distance matrix calculated from the sequences in Fig. 1. A phylogenetic tree of these species drawn from the distance matrix by the neighbor-joining method (6) is shown in Fig. 2 .

$P$. cocovenenans is not a pseudomonad in the strict sense but could be a member of the genus Burkholderia because in terms of DNA relatedness it is closer to $B$. cepacia than to $P$. aeruginosa (16); its main respiratory quinone is ubiquinone Q-8; it contains intracellular poly- $\beta$-hydroxybutyrate, does not pro-

TABLE 1. Genetic distances ${ }^{a}$

\begin{tabular}{|c|c|c|c|c|c|c|c|c|c|}
\hline \multirow{2}{*}{ pecies or strain } & \multicolumn{9}{|c|}{$\begin{array}{l}\text { No. of nucleotide differences with or } \\
\text { evolutionary distance from: }{ }^{b}\end{array}$} \\
\hline & 1 & 2 & 3 & 4 & 5 & 6 & 7 & 8 & 9 \\
\hline $\begin{array}{l}\text { 1. B. cepacia ATCC } \\
25416\end{array}$ & & 8 & 4 & 5 & 29 & 32 & 71 & 39 & 65 \\
\hline $\begin{array}{l}\text { 2. B. cocovenenans } \\
\text { NCIMB } 12451\end{array}$ & 2.9 & & 9 & 6 & 32 & 30 & 71 & 40 & 63 \\
\hline B. $r$ & 1.4 & 3.2 & & 6 & 25 & 30 & 68 & 41 & 63 \\
\hline B. $g$ & 1.8 & 2.2 & 2.2 & & 30 & 31 & 72 & 41 & 63 \\
\hline 5. B. solanacearum & 10.5 & 11.6 & 9.0 & 10.8 & & 8 & 66 & 38 & 61 \\
\hline 6. $E$ & 11.2 & 10.8 & 10.8 & 11.2 & 2.9 & & 68 & 37 & 59 \\
\hline 7. $B$ & 25.1 & 25.1 & 24.0 & 25.4 & 23.3 & 24.0 & & 76 & 68 \\
\hline 8. C. $t$ & 14.1 & 14.4 & 14.8 & 14.8 & 13.7 & 13.3 & 26.8 & & 55 \\
\hline 9. E. coli & 23.5 & 22.7 & 22.7 & 22.7 & 22.0 & 21.3 & 24.0 & 19.8 & \\
\hline
\end{tabular}

${ }^{a}$ For demonstrated partial 16S rRNA gene sequences (Fig. 1) (omitting positions $5,6,11,12$, and 37 to 58 ).

${ }^{b}$ Above and below the diagonal, respectively. duce phenazine or fluorescent pigment, has a weak oxidase reaction, grows at a low $\mathrm{pH}$, is resistant to polymyxin; and its substrate utilization pattern is very similar to that of $B$. cepacia. The classificatory deduction from phenotypic characteristics and DNA relatedness was verified by a genomic phylogenetic study of the 16S rRNA gene fragment data. It was shown that $P$. cocovenenans is a close relative of $B$. gladioli and $B$. cepacia. The distance between them was less than those between $B$. gladioli and $B$. pickettii. We therefore propose that $P$. cocovenenans be transferred to the genus Burkholderia as Burkholderia cocovenenans (van Damme et al. 1960) comb. nov.

Description of Burkholderia cocovenenans (van Damme, Johannes, Cox, and Berends 1960) comb. nov. Burkholderia cocovenenans (co.co.ve'ne.nans. M.L. n. Cocos, genus of coconut; L. v. veneno, to poison; M.L. part. adj. cocovenenans, coconut poisoning). The description below is based on studies by us

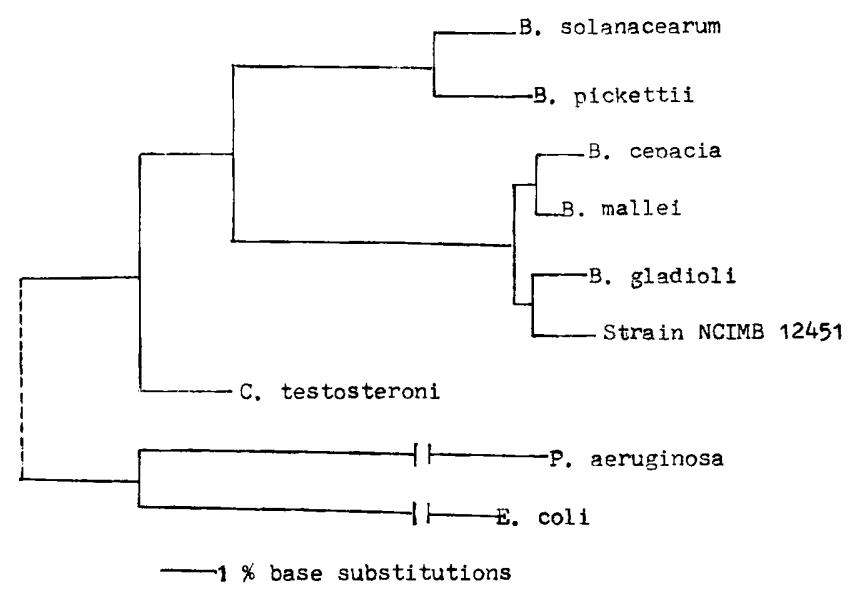

FIG. 2. Relationship of strain NCIMB 12451 to some related species. 
TABLE 2. Diagnostic characteristics for distinguishing B. cocovenenans from other Burkholderia species ${ }^{a}$

\begin{tabular}{|c|c|c|c|c|c|c|c|c|c|c|c|}
\hline Test or characteristic & $\begin{array}{c}\text { B. } \\
\text { cocovenenans }\end{array}$ & $\begin{array}{c}B . \\
\text { gladiolic }\end{array}$ & $\begin{array}{c}B . \\
\text { cepacia }^{c}\end{array}$ & $\begin{array}{c}B . \\
\text { caryophyllic }\end{array}$ & $\begin{array}{c}B . \\
\text { pseudomalleic }\end{array}$ & $\begin{array}{c}B . \\
\text { mallei }^{c}\end{array}$ & $\begin{array}{c}B . \\
\text { solanacearum }^{c}\end{array}$ & $\begin{array}{c}B . \\
\text { pickettii }^{c}\end{array}$ & $\begin{array}{c}B . \\
\text { plantariid }^{d}\end{array}$ & $\begin{array}{c}B . \\
\text { glumae }\end{array}$ & $\begin{array}{c}B . \\
\text { vandiid }\end{array}$ \\
\hline Dentrification & - & - & - & + & + & $\mathbf{v}$ & + & + & + & + & + \\
\hline Oxidase & - & $\mathrm{v}$ & $\mathrm{v}$ & - & + & + & + & + & + & $\mathrm{v}$ & + \\
\hline Arginine dihydrolase & - & - & - & + & + & + & - & - & - & - & \\
\hline Hydrolysis of gelatin & + & + & $\mathrm{v}$ & - & + & + & - & - & + & + & + \\
\hline Hydrolysis of starch & - & - & - & - & + & $\mathrm{v}$ & - & - & - & - & - \\
\hline \multicolumn{12}{|l|}{ Utilization of: } \\
\hline L-Rhamnose & - & - & $\mathrm{v}$ & + & - & - & - & - & $\mathrm{w}$ & - & - \\
\hline Maltose and starch & - & - & $(-)$ & - &,+- & - & - & - & - & - & - \\
\hline Citrate & + & + & + & + & + & - & + & - & + & & - \\
\hline Mucate & + & + & + & + & - & - & + & + & & & \\
\hline Malonate & + & + & + & + & - & $\mathbf{v}$ & - & + & + & & \\
\hline Glutarate & - & $\mathrm{v}$ & + & - & $\mathbf{v}$ & $\mathbf{v}$ & - & $\mathrm{v}$ & - & - & - \\
\hline Adipate & + & + & + & - & + & + & - & + & + & + & + \\
\hline Azelate and sebacate & + & + & + & - & + & $\mathrm{v},-$ & $\mathrm{v}$ & + & $\mathrm{w}$ & + &,-+ \\
\hline D-Tartrate & + & + & - & - & - & - & - & - & + & - & + \\
\hline Glycolate & - & - & $\mathrm{v}$ & + & - & - & $\mathrm{v}$ & + & + & w & - \\
\hline Aconitate & + & + & + & + & + & - & + & + & & & \\
\hline Levulinate & - & - & + & - & + & - & $\mathbf{v}$ & + & - & - & - \\
\hline Citraconate & + & + & + & - & - & - & - & + & $\mathrm{w},+$ & w & + \\
\hline Mesaconate & $\mathrm{v}$ & + & - & - & - & - & - & - & $\mathrm{w}$ & - & + \\
\hline Erythritol & - & - & - & - & + & - & - & - & - & & \\
\hline 2,3-Butylene glycol & - & - & + & + & - & - & - & $\mathrm{v}$ & - & - & - \\
\hline Benzoate & $\mathrm{w}$ & + & + & - & + & + & - & - & - & - & - \\
\hline D-Alanine & + & + & + & - & + & + & + & + & & & \\
\hline L-Valine & $\mathrm{v}$ & + & $\mathrm{v}$ & $\mathrm{v}$ & + & $\mathrm{v}$ & - & + & & & \\
\hline Leucine & - & + & + & - & + & - & - & - & + & + & + \\
\hline DL- $\alpha$-Aminobutyrate & $\mathbf{v}$ & $\mathbf{v}$ & - & - & - & $\mathbf{v}$ & - & - & - & - & - \\
\hline Kynurenate and anthranilate & + &,$+ \mathrm{v}$ & + & - & + &,$- \mathrm{v}$ & - &,+- & & & \\
\hline Ethanolamine & + & $\mathrm{v}$ & + & - & + & - & - & - & - & + & - \\
\hline Benzylamine & - & $(-)$ & $\mathrm{v}$ & - & - & - & - & - & & & \\
\hline Acetamide & - & - & $\mathbf{v}$ & - & - & - & - & - & w & - & - \\
\hline Nicotinate & + & - & $\mathbf{v}$ & - & - & - & - & - & + & w & + \\
\hline $\mathrm{G}+\mathrm{C}(\mathrm{mol} \%)$ & 68 & 67.9 & 66.6 & 64.6 & 68 & 68 & 66.6 & 64 & 64 & 69.6 & 68.5 \\
\hline
\end{tabular}

${ }^{a}(-)$, present in more than $90 \%$ of the strains; $v$, present in 10 to $90 \%$ of the strains; $w$, weakly positive.

$b$ 17 strains.

${ }^{c}$ The data are from reference 5.

${ }^{d}$ Type strain. The data are from reference 14.

(16) of the type strain, NCIB 9450, strain NCIMB 12451, 16 other strains, and two strains (including the type strain) described by Gwynn et al. (3).

Rods 0.3 to 0.5 by 1.6 to $2.0 \mu \mathrm{m}$. Cells occur singly or in pairs and are motile by means of a tuft of (mainly 1 to 5) polar flagella. Cells accumulate poly- $\beta$-hydroxybutyrate as a carbon reserve material. No lipid soluble or fluorescent pigment, but has a greenish-yellow diffusive pigment (toxoflavin) after 1 to 2 days of incubation on potato dextrose agar or other medium. The growth temperature ranges from 6 to $41^{\circ} \mathrm{C}$. The $\mathrm{pH}$ range of growth is 4.0 to 8.0 with an optimum of 6 to 7 . Obligately aerobic. Metabolism is respiratory and never fermentative with oxygen as the terminal electron acceptor. Denitrification is negative; nitrate is reduced to nitrite. Catalase is positive and oxidase is scored as negative. No growth factor is required. Gelatin is liquefied. Lipase against Tween 80 and lecithinase are produced. Chemoorgantrophic, utilizing a wide range of carbohydrates, organic acids, and amino acids as sources of carbon and energy.

The following compounds are used by most of the species as sole carbon sources: acetate, acetylglycine, acetylsalicylate, aconitate, adipate, $\beta$-alanine, $D-\alpha$-alanine, $L-\alpha-$-alanine, anthranilate, L-arabinose, L-arginine, asparagine, L-aspartate, azelate, butanine, butyrate, caprylate, cellobiose, choline, citraconate, citrate, ethanol, ethanolamine, D-fructose, D-fucose, L-fucose, fumarate, D-galactose, gluconate, D-glucose, glucuronate, glycerol, $\beta$-glycerophosphate, guanosine, heptylate, L-histidine, DL$\beta$-hydroxybutyrate, $i$-inositol, 2-ketoglutarate, kynurenate, DLlactate, L-lysine, DL-malate, malonate, mannitol, mannose, melibiose, nicotinate, pelargonate, L-proline, protocatechuate, pyruvate, ribose, salicin, sarcosine, sebacate, serine, sorbitol, succinate, D-tartrate, L-tartrate, meso-tartrate, DL-threonine, trehalose, L-tyrosine, urate, xylitol, and D-xylose.

Table 2 lists the diagnostic characteristics for the differentiation of $B$. cocovenenans from other Burkholderia species $(1,5$, $11)$.

The type strain is NCIB 9450 . The following results were obtained for this strain by tests that are not universally positive or negative for the 18 strains of $B$. cocovenenans: the strain cannot utilize adonitol, $\alpha$-aminovalerate, DL- $\alpha$-aminobutyrate, DL- $\alpha$-aminobutyrate, benzoate, catechol, hippurate, L-phenylalanine, or $p$-phthalate as sole carbon sources but is able to utilize mesaconate as a sole carbon source. The $\mathrm{G}+\mathrm{C}$ content of the DNA is $69 \pm 0.5 \mathrm{~mol} \%$ (from thermal denaturation).

DNA-DNA hybridization experiments and partial 16S rRNA gene sequence (positions 44 to 337 in $E$. coli) indicate that this species is closely related to $B$. gladioli and B. cepacia.

Strains have been isolated from local fermented coconut food (bongkrek) in Indonesia, fermented cornmeal in China, deteriorated white fungus (T. fuciformis), and soil. 
Nucleotide sequence accession number. The partial sequence of the $B$. cocovenenans $16 \mathrm{~S}$ rRNA gene has been deposited in EMBL under accession number X87334.

\section{REFERENCES}

1. Azegami, K., K. Nishiyama, Y. Watanabe, I. Kadota, A. Ohuchi, and C. Fukazawa. 1987. Pseudomonas plantarii sp. nov., the causal agent of rice seedling blight. Int. J. Syst. Bacteriol. 37:144-152.

1a.Collins, M. D. 1985. Isoprenoid quinone analysis in bacterial classification and identification, p. 267-287. In M. Goodfellow and D. E. Minnikin (ed.), Chemical methods in bacterial systematics. Academic Press, London.

2. Gerhardt, P., R. G. E. Murray, R. N. Costilow, E. W. Nester, W. A. Wood, N. R. Krieg, and G. B. Phillips (ed.). 1981. Manual of methods for general bacteriology. American Society for Microbiology, Washington, D.C.

3. Gwynn, M. N., S. J. Box, A. G. Brown, and M. L. Gilpin. 1988. MM 42842, a new member of the monobactam family produced by Pseudomonas cocovenenans. I. Identification of the producing organism. J. Antibiot. (Tokyo) 41:1-6.

4. Palleroni, N. J. 1984. Genus I. Pseudomonas Migula 1894, 237 AL, p. 141-199. In N. R. Krieg and J. G. Holt (ed.), Bergey's manual of systematic bacteriology, vol. 1. The Williams \& Wilkins Co., Baltimore.

5. Palleroni, N. J., and B. Holmes. 1981. Pseudomonas cepacia sp. nov., nom. rev. Int. J. Syst. Bacteriol. 31:479-481.

6. Saitou, N., and M. Nei. 1987. The neighbour-joining method: a new method for reconstructing phylogenetic trees. Mol. Biol. Evol. 4:406-425.

7. Sambrook, J., E. F. Fritsch, and T. Maniatis. 1989. Molecular cloning: a laboratory manual, 2nd ed. Cold Spring Harbor Laboratory Press, Cold Spring Harbor, N.Y.

8. Skerman, V. B. D., V. McGowan, and P. H. A. Sneath (ed.). 1980. Approved lists of bacterial names. Int. J. Syst. Bacteriol. 30:225-420.
9. Stanier, R. Y., N. J. Palleroni, and M. Doudoroff. 1966. The aerobic pseudomonads: a taxonomic study. J. Gen. Microbiol. 43:159-271.

10. Toschka, N. Y., P. Hopfl, W. Ludwig, K. H. Schleifer, N. Ulbrich, and V. A. Erdmann. 1988. Complete nucleotide sequence of a 16S ribosomal RNA from Pseudomonas aenuginosa. Nucleic Acids Res. 16:2248.

11. Urakami, T., C. Ito-Yoshida, H. Araki, T. Kijima, K.-I. Suzuki, and K. Komagata. 1994. Transfer of Pseudomonas plantarii and Pseudomonas glumae to Burkholderia as Burkholderia spp. and description of Burkholderia vandii sp. nov. Int. J. Syst. Bacteriol. 44:235-245.

12. van Damme, P. A., A. G. Johannes, H. C. Cox, and W. Berends. 1960. On toxoflavin, the yellow poison of Pseudomonas cocovenenans. Recl. Trav. Chim. Pays-Bas. Belg. 79:255-267.

13. Yabuuchi, E., Y. Kosako, H. Oyaizu, I. Yano, H. Hotta, Y. Hashimoto, T. Ezaki, and M. Arakawa. 1992. Proposal of Burkholderia gen. nov. and transfer of seven species of the genus Pseudomonas homology group II to the new genus, with the type species Burkholderia cepacia (Palleroni and Holmes 1981) comb. nov. Microbiol. Immunol. 36:1251-1275.

14. Yang, D., Y. Oyaizu, H. Oyaizu, G. J. Olsen, and C. R. Woese. 1985. Mitochondrial origins. Proc. Natl. Acad. Sci. USA 82:4443-4447.

15. Young, J. P. W., H. L. Downer, and B. D. Eardly. 1991. Phylogeny of the phototrophic Rhizobium strain BTAi1 by polymerase chain reaction-based sequencing of a 16S rRNA gene segment. J. Bacteriol. 173:2271-2277.

16. Zhao, N.-X., M.-S. Ma, Y.-P. Zhang, and D.-C. Xu. 1990. Comparative description of Pseudomonas cocovenenans (van Damme, Johannes, Cox, and Berends 1960) NCIB 9450 ${ }^{\mathrm{T}}$ and strains isolated from cases of food poisoning caused by consumption of fermented corn flour in China. Int. J. Syst. Bacteriol. 40:452-455.

17. Zhao, N.-X., D.-C. Xu, D.-Y. Zhang, Z.-C. Zhao, C.-L. Chin, and L.-R. Jiang. 1988. Study on the fermented corn flour poisoning bacteria. Microbiol. J. 1:52-56. 